\title{
A meta-analysis of proinflammatory cytokines in chronic heart failure
}

\author{
Mao Liu, ${ }^{1}$ Jian Chen, ${ }^{1}$ Dan Huang, ${ }^{1}$ Jianting $\mathrm{Ke}^{2}{ }^{2}$ Wei Wu${ }^{1}$
}

\begin{abstract}
${ }^{1}$ Department of Cardiology, The Fifth Affiliated Hospital of Sun Yat-Sen University, Zhuhai, People's Republic of China ${ }^{2}$ Department of Nephrology, The Fifth Affiliated Hospital of Sun Yat-Sen University, Zhuhai, People's Republic of China
\end{abstract}

\section{Correspondence to} Professor Wei Wu, Department of Cardiology, The Fifth Affiliated Hospital of Sun YatSen University, No. 52, Meihua East Rd, Zhuhai 519000 , People's Republic of China; wu.wei@medmail.com.cn

Received 19 November 2013 Revised 4 June 2014 Accepted 18 August 2014

\section{(1) cossmatk}

To cite: Liu M, Chen J, Huang $D$, et al. Heart Asia 2014;6:130-136.

doi:10.1136/heartasia-2013010484

\section{ABSTRACT}

Background Previous studies suggested that inflammation was involved in chronic heart failure (CHF), but their sample sizes were small.

Objective To summarise the clinical cytokine data systematically and emphasise the importance of proinflammatory cytokines in the pathogenesis of $\mathrm{CHF}$, we conducted a meta-analysis of relevant literatures. Methods Articles about cytokines and CHF were searched in Pubmed, EMBASE, Cochrane Library, Chinese National Knowledge Infrastructure and Chinese Wanfang Database. The pooled effects were measured by weighted mean difference (MD) and $95 \% \mathrm{Cl}$, which were calculated by RevMan 5.1 software.

Results Finally, a total of 28 studies were included. Compared with normal control subjects, concentrations of tumour necrosis factor- $\alpha$ (TNF- $\alpha$ ), interleukin-6 (IL-6), $\mathrm{IL}-1 \beta$ and $\mathrm{C}$ reactive protein (CRP) in the peripheral blood in CHF patients are significantly increased. The overall MDs with $95 \%$ Cls for TNF- $\alpha, I L-6$, CRP and IL$1 \beta$ were $2.59 \mathrm{pg} / \mathrm{ml}(2.14 \sim 3.05, p<0.00001), 5.49 \mathrm{pg} /$ $\mathrm{mL}(4.68 \sim 6.29, \mathrm{p}<0.00001), 11.45 \mathrm{mg} / \mathrm{dL}$

(7.68 15.23, $p<0.00001)$ and $0.11 \mathrm{pg} / \mathrm{mL}(0.09 \sim 0.14$, $p<0.00001)$. The mortality of elevated IL-6 group was significantly higher than control group $(\mathrm{OR}=6.73,95 \%$ Cl 2.39 18.93, $p=0.0003$ ).

Conclusions Concentrations of TNF- $\alpha, I L-6, I L-1 \beta$ and CRP are significantly higher in CHF patients than in control subjects. Proinflammatory cytokines play an import role in the pathogenesis of CHF.

\section{INTRODUCTION}

Heart failure is a complex clinical syndrome that results from any structural or functional impairment of ventricular filling or ejection of blood. The lifetime risk of developing heart failure is $20 \%$ for Americans $\geq 40$ years old. Over 650,000 new cases are diagnosed every year in America. ${ }^{1} 2$ Disorders of the pericardium, myocardium, endocardium, heart valves, or great vessels may all lead to heart failure. ${ }^{2}$ In the past few years, researchers have realised that immune-inflammatory activation may play an important role in the pathogenesis of chronic heart failure (CHF). ${ }^{3}$ Several studies have reported that levels of proinflammatory cytokines, such as tumour necrosis factor- $\alpha$ (TNF- $\alpha$ ), interleukin-6 (IL-6), IL-1 $\beta$ and $C$ reactive protein (CRP) are increased in CHF patients. ${ }^{4-8}$ They may also be good predictors for improvement and readmission in $\mathrm{CHF}^{4}{ }^{9}$ However, the sample sizes of these studies are rather small. Moreover, no systematic review with a quantitative synthesis of the cytokines of CHF patients compared to controls has been reported yet. Consequently, in the present study, we systematically reviewed available data and conducted a meta-analysis to enhance the importance of proinflammatory cytokines in the disease process of CHF.

\section{METHODS}

\section{Search methods}

Two investigators (JC and JK) independently performed electronic searches on cytokines and $\mathrm{CHF}$ in Pubmed, EMBASE, Cochrane Library, China National Knowledge Infrastructure (CNKI), and Wanfang Database from their inception to November 2nd 2013 with the following terms: TNF- $\alpha$, IL-6, IL-1 $\beta$, CRP, cytokine, inflammatory factor, heart failure and cardiac insufficiency. The reference lists of relevant studies were also searched for any additional trials. The language was restricted to English and Chinese.

\section{Inclusion criteria}

The inclusion criteria for eligible studies were as follows: (1) studies should be published in a peer reviewed journal; (2) study type should be case control study or cohort study; (3) comparison should be made between CHF patients and normal controls. As for the predictive value of cytokines, $\mathrm{CHF}$ patients should be divided into two groups (elevated cytokine group vs control group) and followed-up for at least 12 months; (4) provided sufficient data of cytokine concentrations; (5) sample size should be more than 20. Patients with acute myocardial infarction, chronic inflammatory diseases, autoimmune disease, acute infection, cancer and severe renal failure were excluded. Meeting abstracts, case reports, editorials and reviews were excluded.

\section{Data extraction and quality assessment}

In the data extraction process, we collected study type, the first author's name, year of publication, country in which the study was performed, population characteristics, sample size (CHF patients and controls), mean age, gender, sample source, cytokines and measure techniques of each study. NewcastleOttawa quality assessment scale (NOS) ${ }^{10}{ }^{11}$ was used to assess the quality of these included studies. A case control study can be awarded a highest score of nine. Data extraction and quality assessment was completed by two investigators (ML and JC) independently. Disagreements were resolved by discussion.

\section{Statistical analysis}

In this article, Cochrane $\mathrm{Q}$ test and $\mathrm{I}^{2}$ were used to investigate the heterogeneity. The $\mathrm{p}$ value for heterogeneity tests was set at 0.10 , others were 0.05 . All the $\mathrm{p}$ values were 2 -tailed. If $\mathrm{I}^{2}>50 \%$, a random-effect model was chosen. Accordingly, we 
ran a fixed-effect model if $\mathrm{I}^{2}<50 \%$. Funnel plot was used to evaluate the publication bias. Weighted mean differences (MD) and $95 \%$ CIs were calculated for the concentrations of TNF- $\alpha$, IL-6 and IL-1 $\beta$. As for mortality, an OR with 95\% CI was selected. All statistical tests were performed with Review Manager 5.1 for Windows available from the Cochrane Collaboration.

\section{RESULTS}

Literature search

A total of 1815 citations were found in the initial search. Animal experimental studies were excluded. After removing duplicates and reading the titles, 86 articles were entered into the full text review process. Among them, 38 studies were excluded for improper control groups (not CHF patients vs normal subjects). Double publications were found in 15 studies, which were all from China. Finally, 30 relevant articles ${ }^{5-8} \quad 12-37$ met the selection criteria and were included for analysis in this review. In all the eligible studies, samples (serum or plasma) were collected from peripheral blood. TNF- $\alpha$, IL-6 and IL-1 $\beta$ concentrations were compared in picogram per millilitre (pg/ $\mathrm{mL})$. CRP concentration was milligram per decilitre $(\mathrm{mg} / \mathrm{dL})$. Three studies 183637 reported the predictive value of IL- 6 for the mortality in CHF patients. The mean duration of follow-up was 12-18 months. Flow diagram and main characteristics of included studies were shown in figure 1 and table 1 , respectively.

\section{Comparison of TNF- $\alpha$ concentration between CHF patients and control subjects}

As shown in figure 2, 19 studies $^{5-8}$ 16 $^{18-31}$ incorporating 1852 participants were included in the comparison of TNF- $\alpha$ concentration between CHF patients and control subjects. We selected a random-effect model because of a statistical heterogeneity found in this analysis. To assess the publication bias, a funnel plot was made and shown in figure 3 . The results indicated that concentration of TNF- $\alpha$ was significantly higher in CHF patients than control subjects. The overall MD for TNF- $\alpha$ was $2.59 \mathrm{pg} / \mathrm{ml}(95 \%$ CI $(2.14$ to 3.05$), \mathrm{p}<0.00001)$.

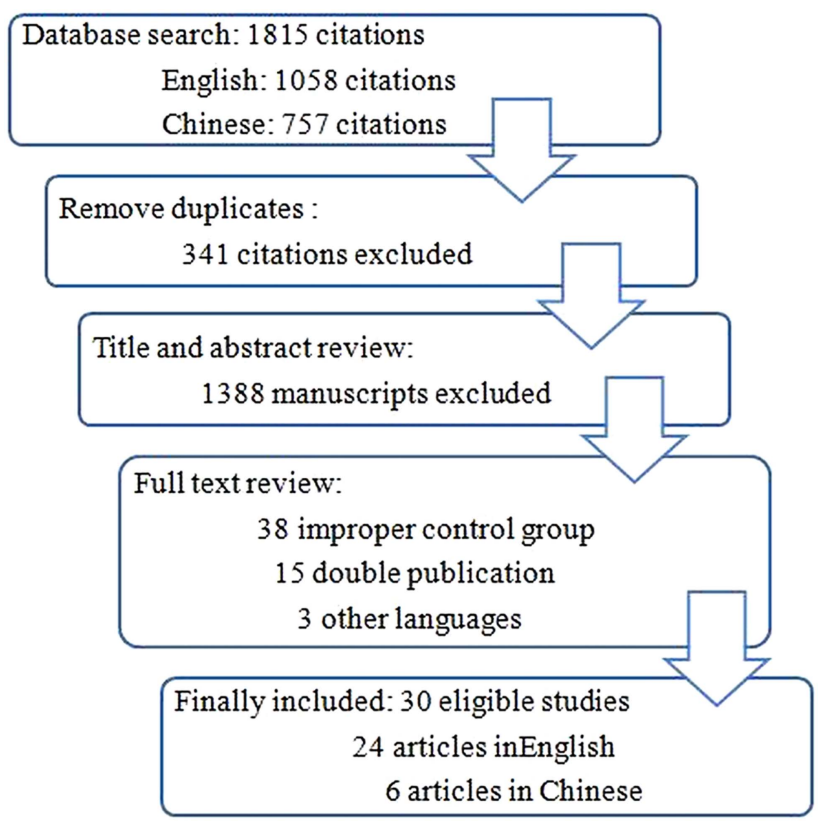

Figure 1 Flow diagram of the literature search process.
Comparison of IL- 6 concentration between CHF patients and control subjects

Data of IL- 6 concentrations were collected in 733 CHF patients

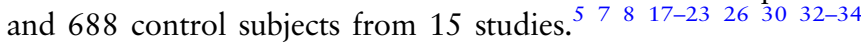
Cochrane $\mathrm{Q}$ test indicated a significant heterogeneity among these studies $(\mathrm{p}<0.001), \mathrm{I}^{2}>50 \%$. Accordingly, a random-effect model was selected (figure 4). Compared with normal control subjects, concentration of IL- 6 was higher in CHF patients. The overall MD for IL-6 was $5.49 \mathrm{pg} / \mathrm{mL}$ (95\% CI (4.68 to 6.29), $\mathrm{p}<0.00001)$.

\section{Comparisons of CRP and IL-1及 concentrations between CHF patients and control subjects}

CRP and IL-1 $\beta$ concentrations in CHF patients and normal control subjects were detected in 1167 participants from 10 studies ${ }^{8} 12-151722313435$ and 233 participants from three eligible studies, ${ }^{5} 1821$ respectively. We chose a random-effect model in the pooled analysis for CRP $\left(\mathrm{I}^{2}=99 \%\right)$ and a fixed-effect model in the pooled analysis for IL-1 $\beta\left(\mathrm{I}^{2}=34 \%\right)$. From the results displayed in figure 5, CHF patients had a higher level of CRP concentration. The overall MD for CRP was $11.45 \mathrm{mg} / \mathrm{dL}$ (95\% CI (7.68 to 15.23$), \mathrm{p}<0.00001)$. The concentration of IL-1 $\beta$ was also statistically higher in CHF patients than control subjects (MD $0.11 \mathrm{pg} / \mathrm{mL}, 95 \%$ CI $(0.09$ to 0.14$), \mathrm{p}<0.00001$; figure 6).

\section{Predictive value of IL- 6 for the mortality in CHF patients} There were three studies ${ }^{18} 3637$ that reported the predictive value of IL-6 vis-a-vis mortality. CHF patients were divided into elevated IL-6 group and control group (concentrations of IL-6 $<$ cut-off points). No statistical heterogeneity was found in this analysis $\left(\mathrm{I}^{2}=36 \%\right)$, and a fixed-effect model was selected (figure 7). The mortality of elevated IL-6 group was significantly higher than control group $(\mathrm{OR}=6.73,95 \% \mathrm{CI}$ (2.39 to 18.93$)$, $\mathrm{p}=0.0003)$.

\section{DISCUSSION}

The findings from our meta-analysis suggest that concentrations of TNF- $\alpha$, IL-6, IL-1 $\beta$ and CRP in the peripheral blood of CHF patients were significantly higher than in the control subject. The serum level of IL- 6 may be a useful marker to predict the mortality in patients with CHF.

Early in 1990, Levine et $a l^{38}$ were the first to report a possible role of proinflammatory cytokines in $\mathrm{CHF}$. They found that circulating levels of TNF were increased in cachectic patients with CHF. Subsequently, more studies concerning the role of proinflammatory cytokines in $\mathrm{CHF}$ were published. Kinugawa et $a l^{19}$ measured the serum IL-6 and TNF- $\alpha$ concentration in $84 \mathrm{CHF}$ patients and 34 controls. Results indicated that significantly elevated serum IL- 6 and TNF- $\alpha$ levels were found in CHF patients. Increase of IL-1 $\beta$ and CRP in CHF were also reported. ${ }^{5} 15$ The Framingham Heart Study ${ }^{39}$ included 732 elderly subjects free of prior myocardial infarction and CHF. During the follow-up (mean 5.2 years), 56 subjects developed CHF. A serum CRP level $>$ or $=5 \mathrm{mg} / \mathrm{dL}$ was associated with a 2.8 -fold increased risk of CHF. There was a $60 \%$ (TNF- $\alpha$ ) to $68 \%$ (IL-6) increase in risk of CHF per tertile increment in cytokine concentration. The results indicated that serum proinflammatory cytokines were associated with increased risk of CHF.

In the present study, we have conducted the first meta-analysis of published literatures to emphasise the importance of proinflammatory cytokines in the pathogenesis of CHF. We pooled 
Table 1 Main characteristic of included studies

\begin{tabular}{|c|c|c|c|c|c|c|c|c|c|}
\hline Study & Year & Country & Population & Patient/control & Age (years) & Sample & Cytokines & Technique & NOS \\
\hline Wu & 2008 & China & $\mathrm{CHF}$ & $246 / 107$ & $57.2 / 56.9$ & Serum & CRP & Olympus AU600 automatic biochemical analyser (Japan) & 8 \\
\hline Lubrano & 2010 & Italy & $\mathrm{CHF}, \mathrm{EF}<40 \%$ & $166 / 48$ & $64 / 48$ & Plasma & $\begin{array}{l}\text { IL-6, TNF- } \alpha, \\
\text { CRP }\end{array}$ & ELISA, Immulite System (DPC, Los Angeles, USA) & 7 \\
\hline Rodriguez-Reyna & 2005 & Mexico & Stable CHF & $128 / 35$ & 59/NA & Serum & TNF- $\alpha$ & ELISA & 6 \\
\hline Kinugawa & 2012 & Japan & $\mathrm{CHF}, \mathrm{EF}<45 \%$ & $106 / 39$ & $59.2 / 55.1$ & Serum & IL-6, TNF- $\alpha$ & CLEIA, Quantikine HS (R\&D Systems, Minneapolis, Minnesota, USA) & 7 \\
\hline Emdin & 2004 & Italy & CHF, NYHA I-IV & $105 / 94$ & $66.7 / 58.9$ & Plasma & IL-6, TNF- $\alpha$ & Immulite Automated Analyser (DPC, Los Angeles, USA) & 7 \\
\hline Kinugawa & 2003 & Japan & $\mathrm{CHF}, \mathrm{EF}<45 \%$ & $84 / 34$ & $59.4 / 56.7$ & Serum & IL-6, TNF- $\alpha$ & CLEIA, Quantikine HS (R\&D Systems, Minneapolis, Minnesota, USA) & 8 \\
\hline Wang & 2009 & China & CHF, NYHA I-IV & $65 / 32$ & $50.6 / 51.5$ & Plasma & IL-6 & Immunoradiometric assay & 6 \\
\hline Rauchhaus & 2000 & Germany & $\mathrm{CHF}$ & $58 / 19$ & $60 / 59$ & Serum & TNF- $\alpha$ & ELISA & 8 \\
\hline Haugen & 2008 & Sweden & CHF, NYHA II-III & $54 / 70$ & $80.1 / 75.2$ & Serum & $\begin{array}{l}\text { IL-1 } \beta, \text { IL-6, } \\
\text { CRP, TNF- } \alpha\end{array}$ & Evidence analyser (Randox Laboratories, UK) & 8 \\
\hline Stumpf & 2003 & Germany & CHF, NYHA II-IV & $50 / 25$ & $66.9 / 63.6$ & Serum & CRP, TNF- $\alpha$ & ELISA & 8 \\
\hline Wang & 2001 & China & CHF, NYHA II-IV & $48 / 30$ & $72.8 / 69.8$ & Serum & IL-6 & ELISA & 7 \\
\hline Greig & 2008 & Spain & $\mathrm{CHF}, \mathrm{EF}<40 \%$ & $42 / 15$ & 56/NA & Serum & IL-6, CRP & ELISA & 6 \\
\hline Pan & 2004 & China & CHF, NYHA III-IV & $37 / 44$ & $62 / 63$ & Serum & IL-6, TNF- $\alpha$ & ELISA, Quantikine HS (R\&D Systems, Minneapolis, Minnesota, USA) & 7 \\
\hline Anker & 1999 & UK & $\begin{array}{l}\text { CHF } \\
\text { without cachectic }\end{array}$ & $36 / 15$ & $58.9 / 57.9$ & Plasma & $\begin{array}{l}\text { IL-1 } \beta, \text { IL-6, } \\
\text { TNF- } \alpha\end{array}$ & ELISA, Immunometric enzyme immunoassay (R\&D Systems, Minneapolis, Minnesota, USA) & 7 \\
\hline Sirera & 2003 & Spain & CHF, NYHA III-IV & $30 / 30$ & 67/NA & Plasma & IL-6, NF- $\alpha$ & ELISA & 6 \\
\hline Milani & 1996 & Germany & $\begin{array}{l}\text { CHF } \\
\text { without cachectic }\end{array}$ & $29 / 25$ & $56 / 41$ & Serum & TNF- $\alpha$ & ELISA & 8 \\
\hline White & 2006 & Canada & CHF, NYHA III-IV & $29 / 15$ & $61.9 / 54.1$ & Serum & CRP, IL-6 & ELISA, Dade Behring N Highly Sensitivity CRP assay (Dade Behring Diagnostics) & 6 \\
\hline Liu & 2008 & China & CHF, NYHA III-IV & $46 / 45$ & $62.2 / 61.7$ & Serum & CRP & LETIA (Beckman LX20 automatic biochemical analyser) & 7 \\
\hline Kosar & 2006 & Turkey & CHF, NYHA III-IV & $25 / 33$ & $61.4 / 60.8$ & Serum & $\begin{array}{l}\text { IL-1 } \beta, \text { IL-6, } \\
\text { TNF- } \alpha, \text { CRP }\end{array}$ & ELISA & 8 \\
\hline Parissis & 1999 & Greece & Cachectic CHF, NYHA III-IV & $25 / 15$ & $64 / 57$ & Plasma & TNF- $\alpha$ & ELISA & 7 \\
\hline Zhang & 2010 & China & CHF, NYHA I-IV & $87 / 35$ & $58.6 / 57.6$ & Serum & CRP & HITACHI 7600 automatic biochemical analyser (Japan) & 6 \\
\hline Mayer & 2005 & Germany & $\begin{array}{l}\text { CHF, EF }<40 \% \\
\text { NYHA II-III }\end{array}$ & $21 / 20$ & $57.6 / \mathrm{NA}$ & Serum & IL-6, TNF- $\alpha$ & Immunometric enzyme immunoassay (R\&D Systems, Minneapolis, Minnesota, USA) & 6 \\
\hline Nishigaki & 1997 & Japan & CHF, NYHA II & $20 / 62$ & $66 / 62$ & Serum & IL-6, TNF- $\alpha$ & ELISA & 8 \\
\hline Niethammer & 2008 & Germany & $\mathrm{CHF}, \mathrm{EF}<40 \%$ & $17 / 20$ & $70 / 56$ & Serum & TNF- $\alpha$ & Quantikine HS (R\&D Systems, Minneapolis, Minnesota, USA) & 7 \\
\hline Genth-Zotz & 2002 & UK & $\mathrm{CHF}, \mathrm{EF} \leq 40 \%$ & $15 / 7$ & $65 / 59$ & Serum & TNF- $\alpha$ & Quantiglo and Quantikine (R\&D Systems, Minnesota, USA) & 6 \\
\hline Toth & 2006 & USA & CHF, NYHA II-IV & $10 / 11$ & $63 / 70$ & Serum & $\begin{array}{l}\text { CRP, IL-6, } \\
\text { TNF- } \alpha\end{array}$ & ELISA & 6 \\
\hline Chen & 2011 & China & CHF, NYHA II-IV & $60 / 20$ & $62.7 / 60.5$ & Serum & CRP & Radioimmunoassay (Dade Behring Diagnostics) & 8 \\
\hline Liao & 2010 & China & CHF, NYHA III & $60 / 50$ & $\begin{array}{l}54-57 / \\
52-67\end{array}$ & Serum & CRP & CL8000 automatic biochemical analyser (Japan) & 6 \\
\hline Orus & 2000 & Spain & CHF, NYHA I-IV & $87 /-$ & $57 /-$ & Plasma & IL-6 & $\begin{array}{l}\text { Immunoenzyme assay } \\
\text { kits (Medgenix, Belgium) }\end{array}$ & 6 \\
\hline Roig & 1998 & Italy & $\mathrm{CHF}, \mathrm{EF}<40 \%$ & $40 /-$ & $57 /-$ & Serum & IL-6 & $\begin{array}{l}\text { Immunoenzyme assay } \\
\text { kits (Medgenix, Belgium) }\end{array}$ & 6 \\
\hline
\end{tabular}

CHF, chronic heart failure; CLEIA, chemiluminescence enzyme immunoassay; CRP, C reactive protein; DPC, Diagnostic Products Corporation; EF, ejection fraction; IL, interleukin; LETIA, latex enhanced turbidimetric immunoassay; MN, Minnesota; NA, not available; NOS, Newcastle Ottawa Quality Assessment Scale; NYHA, New York Heart Association; TNF, tumour necrosis factor. 


\begin{tabular}{|c|c|c|c|c|c|c|c|c|c|c|c|}
\hline \multirow[b]{2}{*}{ Studv or Subgroup } & \multicolumn{3}{|c|}{ CHF } & \multicolumn{2}{|c|}{ Control } & \multirow[b]{2}{*}{ Total } & \multirow{2}{*}{\multicolumn{2}{|c|}{$\begin{array}{cl} & \text { Mean Difference } \\
\text { Weight } & \text { IV, Random. } 95 \% \mathrm{Cl} \\
\end{array}$}} & \multirow{2}{*}{\multicolumn{2}{|c|}{$\begin{array}{c}\text { Mean Difference } \\
\text { IV, Random, } 95 \% \mathrm{CI}\end{array}$}} & \\
\hline & Mean & SD & Total & Mean & SD & & & & & & \\
\hline Anker 1999 & 6.9 & 0.8 & 36 & 7.8 & 0.8 & 15 & $5.8 \%$ & $-0.90[-1.38,-0.42]$ & & & \\
\hline Emdin 2004 & 9.9 & 8.4 & 105 & 6.9 & 4.9 & 94 & $3.0 \%$ & $3.00[1.11,4.89]$ & & - & \\
\hline Genth-Zotz 2002 & 4.2 & 1.6 & 15 & 1.5 & 0.4 & 7 & $5.0 \%$ & $2.70[1.84,3.56]$ & & $\infty$ & \\
\hline Haugen 2008 & 4.96 & 5.43 & 54 & 1.3 & 1.57 & 70 & $3.7 \%$ & $3.66[2.17,5.15]$ & & $-\infty$ & \\
\hline Kinugawa 2003 & 4 & 0.3 & 84 & 2.7 & 0.2 & 34 & $6.1 \%$ & $1.30[1.21,1.39]$ & & $=$ & \\
\hline Kinugawa 2012 & 4.26 & 4.36 & 106 & 2.66 & 0.94 & 39 & $5.0 \%$ & $1.60[0.72,2.48]$ & & $\rightarrow$ & \\
\hline Kosar 2006 & 8.72 & 1.65 & 25 & 1.32 & 0.76 & 33 & $5.4 \%$ & $7.40[6.70,8.10]$ & & - & \\
\hline Lubrano 2010 & 0.98 & 0.2 & 166 & 0.69 & 0.2 & 48 & $6.1 \%$ & $0.29[0.23,0.35]$ & & & \\
\hline Mayer 2005 & 1.51 & 0.49 & 21 & 0.64 & 0.15 & 210 & $6.1 \%$ & $0.87[0.66,1.08]$ & & - & \\
\hline Milani 1996 & 3 & 0.4 & 29 & 0.89 & 0.4 & 25 & $6.1 \%$ & $2.11[1.90,2.32]$ & & " & \\
\hline Niethammer 2008 & 2.87 & 0.65 & 17 & 1.76 & 0.27 & 20 & $6.0 \%$ & $1.11[0.78,1.44]$ & & & \\
\hline Nishigaki 1997 & 10 & 3.3 & 20 & 4.2 & 0.6 & 62 & $3.8 \%$ & $5.80[4.35,7.25]$ & & $\rightarrow$ & \\
\hline Pan 2004 & 7.16 & 1.57 & 37 & 6.04 & 0.52 & 44 & $5.7 \%$ & $1.12[0.59,1.65]$ & & - & \\
\hline Parissis 1999 & 18.3 & 3.5 & 25 & 3.7 & 0.7 & 15 & $3.9 \%$ & $14.60[13.18,16.02]$ & & & $\rightarrow$ \\
\hline Rauchhaus 2000 & 9.3 & 1.1 & 58 & 6.7 & 0.6 & 19 & $5.9 \%$ & $2.60[2.21,2.99]$ & & - & \\
\hline Rodriguez-Reyna 2005 & 6.72 & 0.2 & 128 & 5.5 & 0.2 & 35 & $6.1 \%$ & $1.22[1.15,1.29]$ & & - & \\
\hline Sirera 2003 & 5.1 & 1.5 & 30 & 2 & 0.5 & 30 & $5.6 \%$ & $3.10[2.53,3.67]$ & & - & \\
\hline Stumpf 2003 & 6.5 & 2.9 & 50 & 2.5 & 1.8 & 25 & $4.6 \%$ & $4.00[2.93,5.07]$ & & $\rightarrow$ & \\
\hline Toth 2006 & 1.91 & 0.3 & 10 & 1.52 & 0.15 & 11 & $6.1 \%$ & $0.39[0.18,0.60]$ & & & \\
\hline Total $(95 \% \mathrm{Cl})$ & & & 1016 & & & 836 & $100.0 \%$ & $2.59[2.14,3.05]$ & & $\uparrow$ & \\
\hline $\begin{array}{l}\text { Heterogeneity: } \operatorname{Tau}^{2}=0.8 \\
\text { Test for overall effect: } Z=\end{array}$ & $\begin{array}{l}\text { 3: } \mathrm{Chi}^{2}= \\
11.11(\mathrm{P}\end{array}$ & $\begin{array}{l}1626 . \\
<0.00\end{array}$ & $\begin{array}{l}17, d f= \\
0001)\end{array}$ & $18(P$ & $=0.00$ & 01); $1^{2}$ & 99 & & $\begin{array}{lc}1 & 1 \\
-10 & -5 \\
\text { avours } \mathrm{CHF}\end{array}$ & $\begin{array}{cc}0 & 5 \\
\text { Favour }\end{array}$ & \\
\hline
\end{tabular}

Figure 2 Forest plot displaying random-effect meta-analysis results of difference in TNF- $\alpha$ concentration between chronic heart failure (CHF) patients and control subjects.

and analysed the previous studies together systematically. For each cytokine in the included studies, the measurement unit was the same. However, significant heterogeneity was found in most comparisons. Accordingly, we chose a random-effect model. We thought that the variety of cytokines' measurement techniques in different studies may contribute to this heterogeneity. From the assessment of funnel plot, the publication bias was acceptable. Finally, the pooled results of our study indicated significantly higher proinflammatory cytokines in CHF patients compared with control subjects, which enhanced the importance of the role of proinflammatory cytokines played in the pathogenesis of CHF.

Proinflammatory cytokines are able to modulate cardiac function and ventricular remodelling by a variety of mechanisms. Studies have shown that TNF- $\alpha$ may mediate both negative inotropic effects on the myocardium through direct effects on calcium-dependent processes and impairment of $\beta$-adrenergic responsiveness. ${ }^{3} 40$ TNF- $\alpha$ may also increase baseline catabolism by stimulating apoptosis and induce myocyte necrosis via a cytotoxic mechanism. ${ }^{41}$ IL-6 promotes myocardial hypertrophy, lymphocyte proliferation, and the synthesis of caspases. It can also induce muscle proteolysis in vitro, which will lead to wasting and weight loss. ${ }^{41}$ IL- $1 \beta$ and TNF- $\alpha$ may also increase the activity of total matrix metalloproteinase, and contribute to ventricular dilation and myocardial failure by promoting the remodelling of interstitial collagen. ${ }^{42}$

Furthermore, proinflammatory cytokines are also reported to be independent predictors of cardiovascular events in older persons. In a cohort study ${ }^{9}$ including 2225 participants, blood levels of IL-6, CRP and TNF- $\alpha$ were assessed. After an average follow-up of 3.6 years, IL- 6 was significantly associated with all outcomes (incident coronary heart disease, stroke, and congestive heart failure) and CRP was significantly associated with congestive heart failure events. Another study, which enrolled 118
Figure 3 Funnel plot of included studies in the meta-analysis of TNF- $\alpha$ concentration.

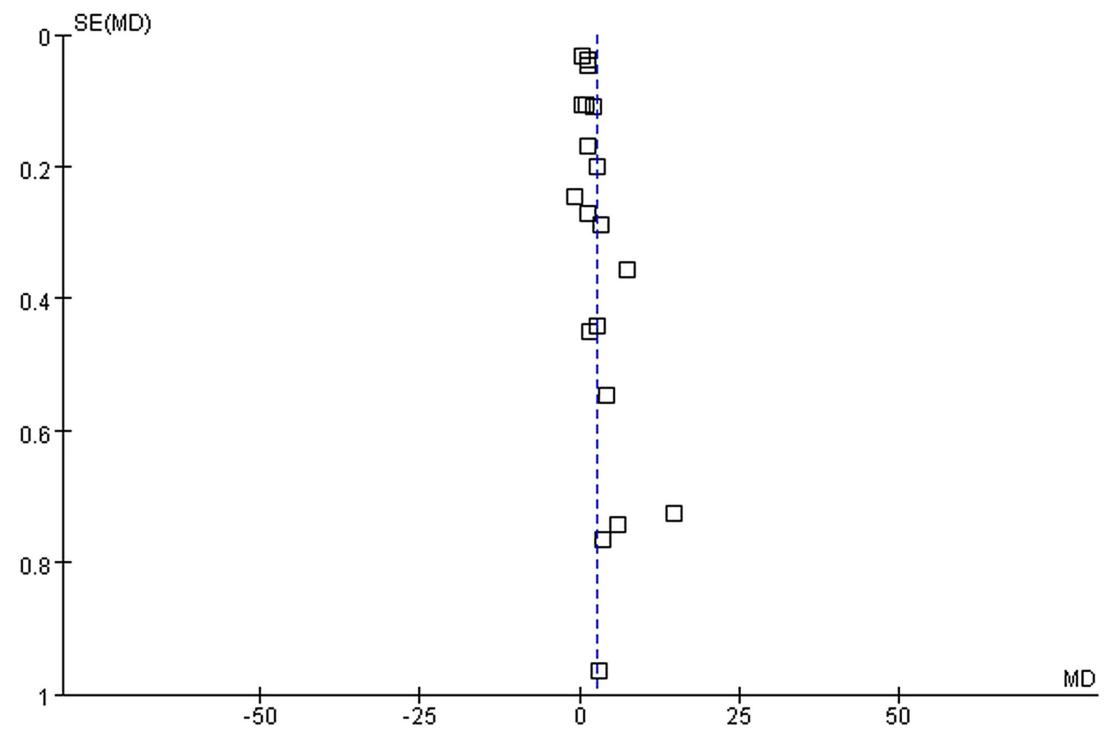




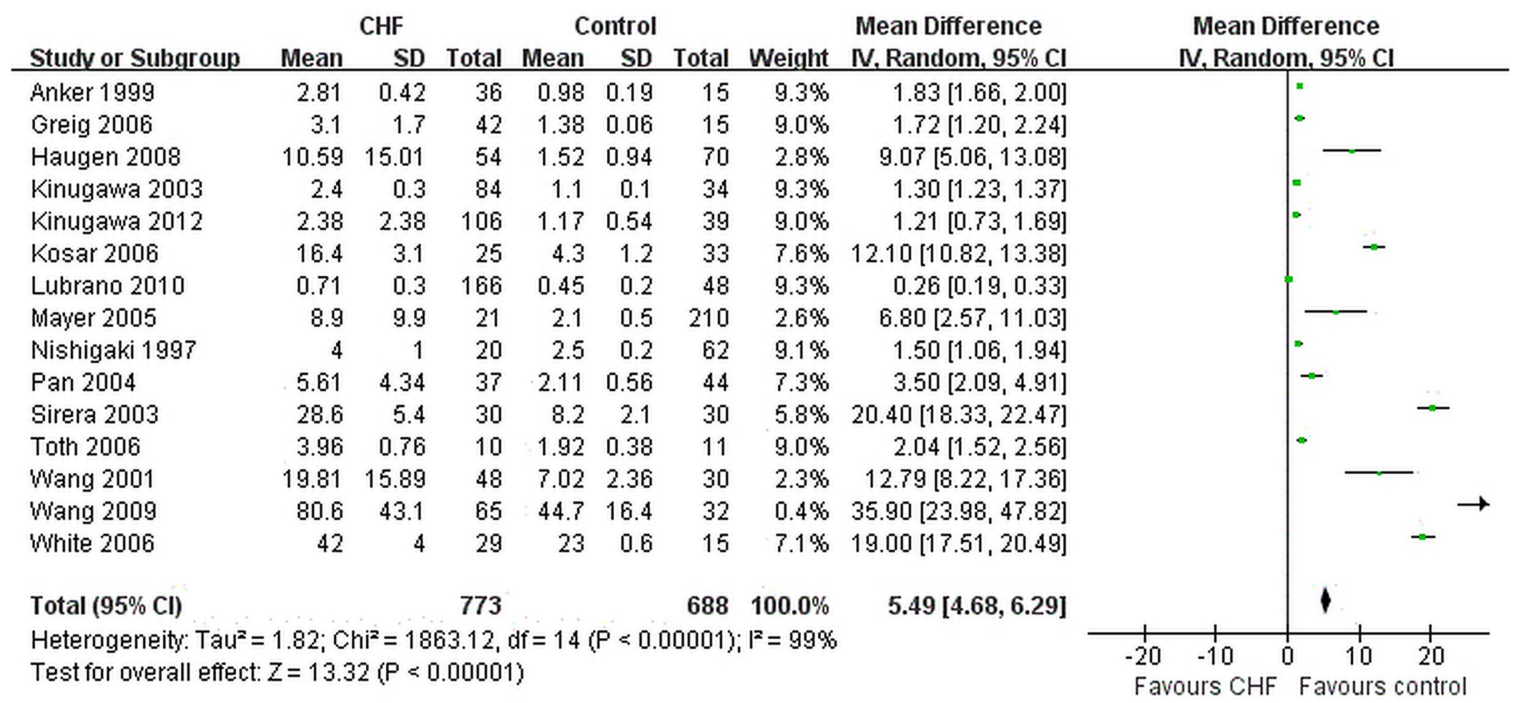

Figure 4 Forest plot displaying random-effect meta-analysis results of difference in IL-6 concentration between chronic heart failure (CHF) patients and control subjects.

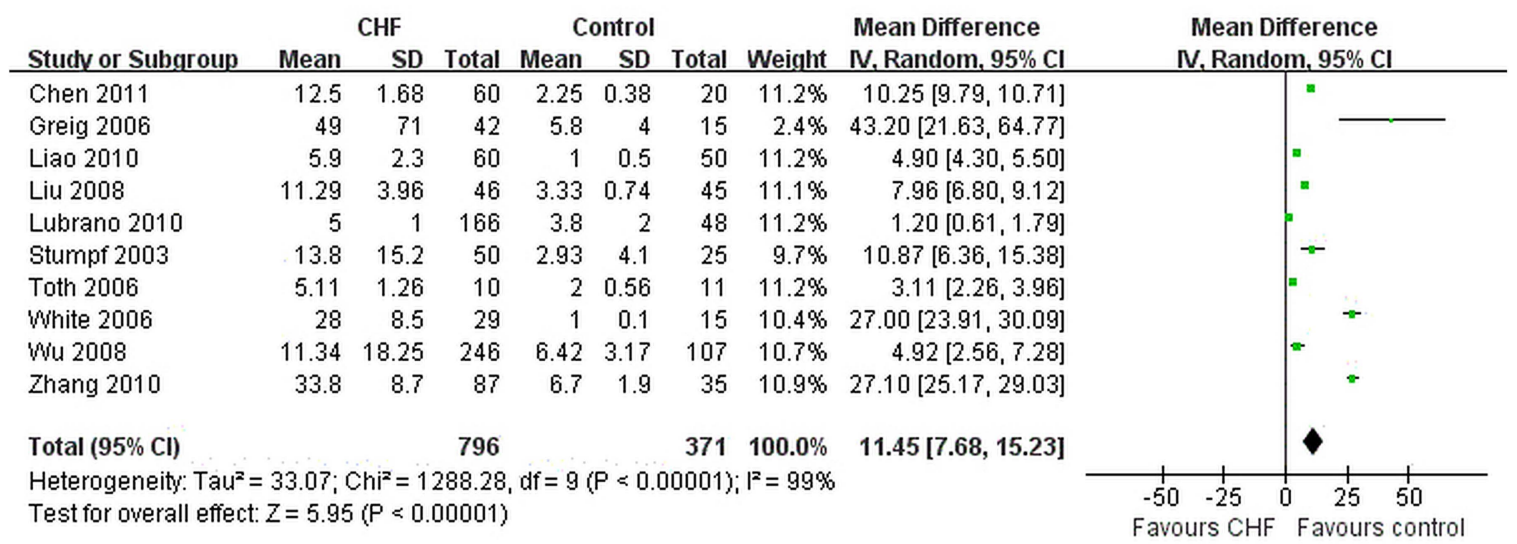

Figure 5 Forest plot displaying random-effect meta-analysis results of difference in C reactive protein concentration between chronic heart failure (CHF) patients and control subjects.

CHF patients, also indicated that the plasma levels of IL- 6 and TNF- $\alpha$ and especially the former, were useful markers to gauge the progression of severity and late cardiac death in patients with $\mathrm{CHF}^{26}$ Our meta-analysis also indicated that the risk of death was significantly increased in patients with elevated IL-6 concentrations. Summarily, elevated proinflammatory cytokines are associated with the development and prognosis of CHF.

Our study has several limitations. First, there was marked heterogeneity across studies. We have to choose random-effect models, which produce wider CIs. Second, only publications in English and Chinese were considered in our search process. Studies in other languages were lost inevitably. Moreover, the number of eligible studies for meta-analysis of IL-1 $\beta$ was relatively small. Further, only TNF- $\alpha$, IL- 6 , IL-1 $\beta$ and CRP levels were scrutinised in the current meta-analysis and other species of proinflammatory cytokines (IL-18) and anti-inflammatory cytokines (IL-10, TGF- $\beta$ ) were not included. Last, throughout the included studies, the cytokines' measurement techniques

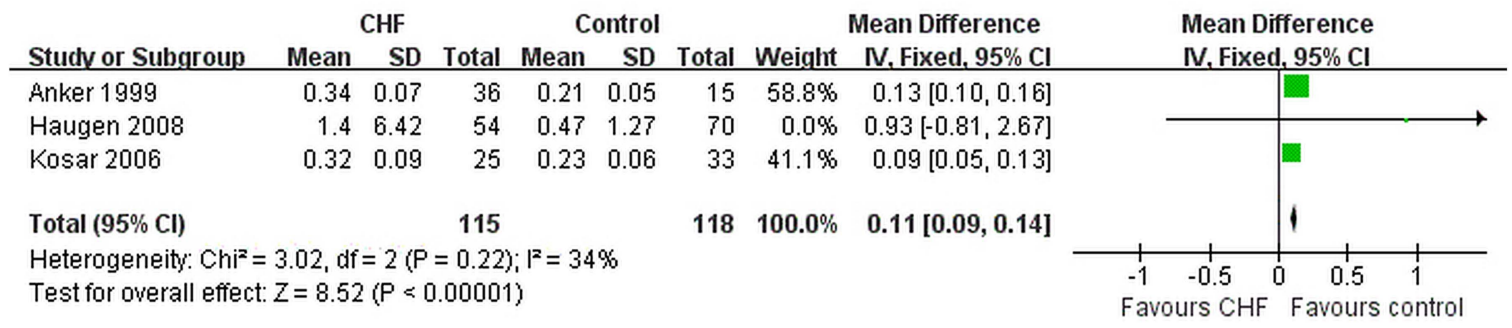

Figure 6 Forest plot displaying fixed-effect meta-analysis results of difference in IL-1 $\beta$ concentration between chronic heart failure (CHF) patients and control subjects. 


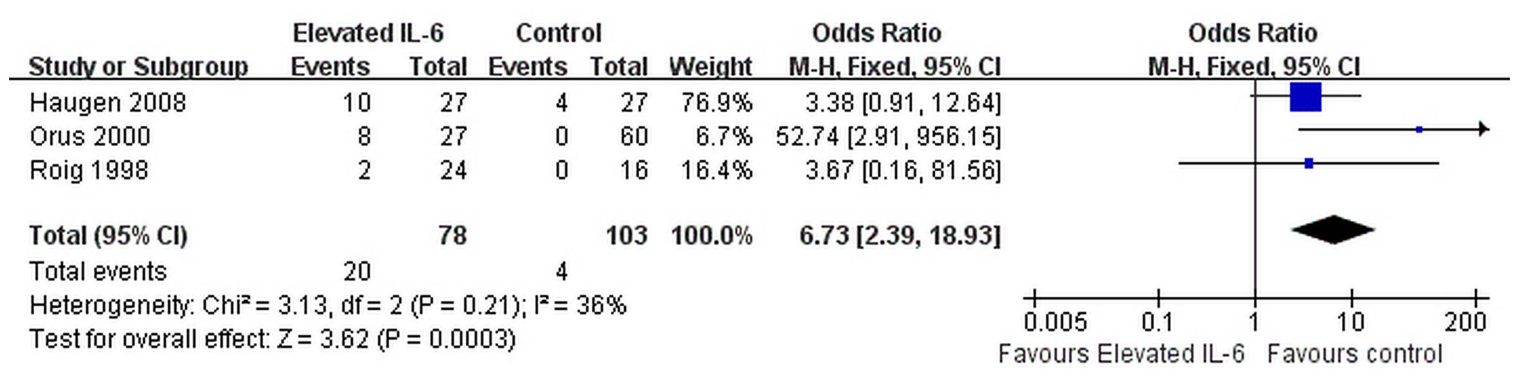

Figure 7 Forest plot comparing mortalities in chronic heart failure (CHF) between the elevated IL-6 group and the control group.

were not the same. As a result, a detection bias cannot be completely excluded in our analysis.

\section{CONCLUSIONS}

In summary, the meta-analysis of available evidence indicates that concentrations of TNF- $\alpha$, IL- 6 , IL-1 $\beta$ and CRP in CHF patients were significantly higher than in control subjects. Proinflammatory cytokines play an import role in the pathogenesis of CHF, and can be used as outcome predictors in CHF patients.

Contributors Conceived and designed the study: JC, ML and WW. Data searching and extraction: JC, JK and ML. Data analysis: JC, DH. Data interpretation: ML and DH. Writing of paper: ML, JC and WW. Equal contributions were made by ML and $\mathrm{JC}$ to this article. The authors did not report any conflict of interest regarding this work and agreed to the final version.

Competing interests None.

Provenance and peer review Not commissioned; externally peer reviewed.

\section{REFERENCES}

1 Djousse L, Driver JA, Gaziano JM. Relation between modifiable lifestyle factors and lifetime risk of heart failure. JAMA 2009;302:394-400.

2 Yancy CW, Jessup M, Bozkurt B, et al. 2013 ACCF/AHA Guideline for the management of heart failure: executive summary: a Report of the American College of Cardiology Foundation/American Heart Association Task Force on Practice Guidelines. J Am Coll Cardiol 2013;62:1495-539.

3 Gullestad L, Aukrust P. Review of trials in chronic heart failure showing broad-spectrum anti-inflammatory approaches. Am J Cardiol 2005;95:17C-23C, $38 \mathrm{C}-40 \mathrm{C}$.

4 Alonso-Martinez JL, Llorente-Diez B, Echegaray-Agara M, et al. C-reactive protein as a predictor of improvement and readmission in heart failure. Eur $J$ Heart Fail 2002;4:331-6.

5 Anker SD, Ponikowski PP, Clark AL, et al. Cytokines and neurohormones relating to body composition alterations in the wasting syndrome of chronic heart failure. Eur Heart J 1999;20:683-93.

6 Genth-Zotz S, von Haehling S, Bolger AP, et al. Pathophysiologic quantities of endotoxin- induced tumor necrosis factor-alpha release in whole blood from patients with chronic heart failure. Am I Cardiol 2002;90:1226-30.

7 Nishigaki K, Minatoguchi S, Seishima M, et al. Plasma Fas ligand, an inducer of apoptosis, and plasma soluble Fas, an inhibitor of apoptosis, in patients with chronic congestive heart failure. J Am Coll Cardiol 1997;29:1214-20.

8 Toth MJ, Ades PA, Tischler MD, et al. Immune activation is associated with reduced skeletal muscle mass and physical function in chronic heart failure. Int I Cardiol 2006;109:179-87.

9 Cesari M, Penninx BW, Newman AB, et al. Inflammatory markers and onset of cardiovascular events: results from the Health $A B C$ study. Circulation 2003;108:2317-22.

10 Mao L, Jian C, Changzhi L, et al. Cytochrome CYP2C19 polymorphism and risk of adverse clinical events in clopidogrel-treated patients: a meta-analysis based on 23,035 subjects. Arch Cardiovasc Dis 2013;106:517-27.

11 Wells GA, Shea B, O'Connell D, et al. The Newcastle-Ottawa Scale (NOS) for assessing the quality of nonrandomised studies in meta-analyses. 2013. http://www. ohri.ca/programs/dinical_epidemiology/oxford.asp

12 Chen W, Wang W, Zhao H, et al. Correlation study on plasma pro-BNP and serum hs-CRP levels and cardiac function of patients with type 2 diabetes mellitus and chronic heart failure(Chinese). Lab Med Clin 2011;08:1286-7, 1289.

13 Liao $Y$. The change and the diagnostic and prognostic values of measurements of cardiac troponin I, high sensitive C reactive protein and B-type natriuretic peptide before or after treatment in patients with heart failure(Chinese). Lab Med 2010;25:92-5.

14 Liu $\mathrm{H}$, Wang R, Huang $\mathrm{S}$, et al. The changes and values of serum hypersensitive $\mathrm{C}$ reactive protein(hs-CRP)and cardiac troponin I(CTnl)in patients with heart failure (Chinese). Chin I Cardiovasc Rev 2008;6:328-30.

15 Zhang J. The value of plasma BNP and CRP in chronic congested heart failure patients and its relation with heart function(Chinese). Chin I Lab Diagn 2010;14:1601-2.

16 Emdin M, Passino C, Prontera C, et al. Cardiac natriuretic hormones, neuro-hormones, thyroid hormones and cytokines in normal subjects and patients with heart failure. Clin Chem Lab Med 2004;42:627-36.

17 Greig D, Castro P, Gabrielli L, et al. Inflammation and endothelial dysfunction in patients with chronic heart failure. Rev Med Chil 2008;136:687-93.

18 Haugen E, Gan LM, Isic A, et al. Increased interleukin-6 but not tumour necrosis factor-alpha predicts mortality in the population of elderly heart failure patients. Exp Clin Cardiol 2008;13:19-24.

19 Kinugawa T, Kato M, Ogino K, et al. Neurohormonal determinants of peak oxygen uptake in patients with chronic heart failure. Jpn Heart J 2003;44:725-34.

20 Kinugawa T, Kato M, Yamamoto $\mathrm{K}$, et al. Proinflammatory cytokine activation is linked to apoptotic mediator, soluble Fas level in patients with chronic heart failure. Int Heart J 2012;53:182-6.

21 Kosar F, Aksoy Y, Ozguntekin G, et al. Relationship between cytokines and tumour markers in patients with chronic heart failure. Eur J Heart Fail 2006;8: 270-4.

22 Lubrano V, Pingitore A, Carpi A, et al. Relationship between triiodothyronine and proinflammatory cytokines in chronic heart failure. Biomed Pharmacother 2010;64:165-9.

23 Mayer B, Holmer SR, Hengstenberg C, et al. Functional improvement in heart failure patients treated with beta-blockers is associated with a decline of cytokine levels. Int I Cardiol 2005; 103:182-6.

24 Milani RV, Mehra MR, Endres S, et al. The clinical relevance of circulating tumor necrosis factor-alpha in acute decompensated chronic heart failure without cachexia. Chest 1996;110:992-5.

25 Niethammer M, Sieber M, von Haehling S, et al. Inflammatory pathways in patients with heart failure and preserved ejection fraction. Int I Cardiol 2008;129:111-17.

26 Pan JP, Liu TY, Chiang SC, et al. The value of plasma levels of tumor necrosis factor-alpha and interleukin- 6 in predicting the severity and prognosis in patients with congestive heart failure. J Chin Med Assoc 2004;67:222-8.

27 Parissis JT, Venetsanou KF, Mentzikof DG, et al. Tumor necrosis factor-alpha serum activity during treatment of acute decompensation of cachectic and non-cachectic patients with advanced congestive heart failure. Scand Cardiovasc J 1999;33: 344-50.

28 Rauchhaus M, Koloczek V, Volk H, et al. Inflammatory cytokines and the possible immunological role for lipoproteins in chronic heart failure. Int I Cardiol 2000;76:125-33.

29 Rodriguez-Reyna TS, Arrieta O, Castillo-Martinez L, et al. Tumour Necrosis Factor alpha and Troponin T as predictors of poor prognosis in patients with stable heart failure. Clin Invest Med 2005;28:23-9.

30 Sirera R, Salvador A, Roldan I, et al. Quantification of proinflammatory cytokines in the urine of congestive heart failure patients. Its relationship with plasma levels. Eur J Heart Fail 2003;5:27-31.

31 Stumpf C, Lehner C, Yilmaz A, et al. Decrease of serum levels of the anti-inflammatory cytokine interleukin-10 in patients with advanced chronic heart failure. Clin Sci (Lond) 2003;105:45-50.

32 Wang $X Q$, Jian ZJ, Xie JC. Changes in plasma concentration of interleukin-6 in elderly patients with coronary artery disease complicated with heart failure (Chinese). Hunan Yi Ke Da Xue Xue Bao 2001;26:231-2.

33 Wang $Y$, Zhou $Y$, Meng $L$, et al. Inflammatory mediators in Chinese patients with congestive heart failure. J Clin Pharmacol 2009;49:591-9.

34 White $\mathrm{M}$, Ducharme A, Ibrahim $\mathrm{R}$, et al. Increased systemic inflammation and oxidative stress in patients with worsening congestive heart failure: improvement after short-term inotropic support. Clin Sci (Lond) 2006;110:483-9. 


\section{Original research}

35 Wu L, Xu DL, Deng LH, et al. Variation of serum soluble CD14 levels in patients with chronic heart failure (Chinese). Nan Fang Yi Ke Da Xue Xue Bao 2008:28:1237-9.

36 Roig E, Orus J, Pare C, et al. Serum interleukin-6 in congestive heart failure secondary to idiopathic dilated cardiomyopathy. Am J Cardiol 1998;82:688-90.

37 Orus J, Roig E, Perez-Villa F, et al. Prognostic value of serum cytokines in patients with congestive heart failure. J Heart Lung Transplant 2000;19:419-25.

38 Levine B, Kalman J, Mayer L, et al. Elevated circulating levels of tumor necrosis factor in severe chronic heart failure. N Engl J Med 1990;323:236-41.
39 Vasan RS, Sullivan LM, Roubenoff R, et al. Inflammatory markers and risk of heart failure in elderly subjects without prior myocardial infarction: the Framingham Heart Study. Circulation 2003:107:1486-91.

40 Finkel MS, Oddis CV, Jacob TD, et al. Negative inotropic effects of cytokines on the heart mediated by nitric oxide. Science 1992;257:387-9.

41 Candia AM, Villacorta HJ, Mesquita ET. Immune-inflammatory activation in heart failure. Arq Bras Cardiol 2007;89:183-90, 201-208.

42 Siwik DA, Chang DL, Colucci WS. Interleukin-1beta and tumor necrosis factor-alpha decrease collagen synthesis and increase matrix metalloproteinase activity in cardiac fibroblasts in vitro. Circ Res 2000;86:1259-65. 